\title{
Detecting and Searching for subglacial lakes through airborne radio-echo sounding in Princess Elizabeth Land (PEL), Antarctica
}

\author{
Xiangbin Cui ${ }^{1 *}$, Shinan Lang $^{2}$, Jingxue $\mathrm{Guo}^{l}$, and Bo $\mathrm{Sun}^{l}$ \\ ${ }^{1}$ Polar Research Institute of China, Shanghai 200136, China \\ ${ }^{2}$ Beijing University of Technology, Beijing 100124, China
}

\begin{abstract}
Over 400 subglacial lakes were discovered in Antarctica through radio-echo sounding (RES) method and remote sensing. Subglacial lakes have significance in lubricating ice-bedrock interface and enhancing ice flow. Moreover, ancient lives may exist in the extreme environment. Since 2015, the "Snow Eagle 601" BT-67 airborne platform has been deployed and applied to map ice sheet and bedrock of Princess Elizabeth Land. One of great motivations of airborne surveys is to detect and search for subglacial lakes in the region. In this paper, we provided preliminary results of RES over both old and new discovered lakes, including Lake Vostok, a potential second large subglacial lake and other lakes beneath interior of the ice sheet in Antarctica.
\end{abstract}

\section{Introduction}

Until now, over 400 subglacial lakes have been found beneath the Antarctic Ice Sheet (AIS) through RES method and remote sensing of changes of ice surface elevation, including the largest and most famous lake of Lake Vostok [1,2]. Normally, subglacial lakes can be identified through their bright, flat and smooth reflections at ice-water interfaces in radargrams, which are different with the surrounding rough, dim and variable reflections at ice-bedrock interfaces [3]. Now, it is well known that subglacial lakes are widespreadly distributed in Antarctica, and many of them are connective and hydrologically active. Subglacial lakes can lubricate ice base and play important roles in altering and affecting ice sheet dynamics and instability [4,5]. Moreover, potential ancient lives in the extreme environments and past climatic proxies in the sediments are also significant [6,7]. However, our knowledge of subglacial lakes beneath the AIS is still limited in regions where have RES data. Subglacial lakes in Princess Elizabeth Land (PEL), the largest area of data blank in Antarctica [8], are unknown. Jamieson et al. [9] infers a large subglacial lake may exist in PEL through satellite data, but the result needs to be identified.

The first fixed-wing aircraft, named "Snow Eagle 601", was deployed by China in 2015. The "Snow Eagle 601" is a BT-67 airplane which has been well used in Antarctica. Airborne instruments, including RES system updated from the High Capability Airborne

\footnotetext{
${ }^{*}$ Corresponding author: cuixiangbin@pric.org.cn
} 
Radar System (HiCARS) maintained by University of Texas, Institute for Geophysics (UTIG), GT-2A gravimeter, CS-3 magnetometer, lase altimeter and camera, were configured and integrated on the airplane. The airborne platform was applied to extensively measure and map properties of the ice sheet, bedrock topography and geological structure in PEL during the 32nd Chinese National Antarctic Research Expeditions (CHINARE 32, 2015/16). One important motivation of the airborne campaign is to detect and search for subglacial lakes in the region. Here, we provided preliminary results of new discovered subglacial lakes in PEL mainly based on qualitative analysis of radargrams.

\section{Methodology}

\subsection{Airborne platform and RES system}

The "Snow Eagle 601" is an aircraft updated from original DC-3 airplane by Basler Turbo Company. It was selected as the first fixed-wing airplane for CHINARE because of its great payload and long range. During scientific operation, flight distance can be more than 2000 $\mathrm{km}$ with all instruments mounted on the airplane and 2-3 operators. The HiCARS developed and maintained by UTIG was installed on the "Snow Eagle 601" after modifications. The HiCARS is capable of sounding the thickest ice sheets, resolving internal ice layers, and detecting characters of subglacial conditions. Two flat-plate Antennas were mounted under each wing. Each antenna can transmit and receive radar signals. Four GPS antennas were mounted on the top of left and right wings and forward and center of the airframe to provide accurate position and attitude information. Detailed performance of the airplane and airborne RES system can be found in Cui et al., 2018 [10]. A field camp was established to support the airborne operation beside the Progress Station skiway. Two GPS base stations were built on the top of two cabins to provide reference GPS data for post data processing.

\subsection{Study area and flight line coverage}

The PEL, the area between Lambert-Amery drainage basin and Wilhelm II Land in East Antarctica (Fig. 1), is the largest data blank in newly released Bedmap 2 dataset [8]. Jamieson et al. [9] infers a large subglacial lake may exist in PEL through analyzing ice sheet surface morphology of satellite data. However, there's no direct measurements to identify the result. During CHINARE 32, network with fan-shaped radial lines was designed to survey the region. The radial lines have advantages of high efficient and extensive range for investigating poorly surveyed regions. Field airborne operations were based on the Progress Station skiway. The flight lines are shown in red lines in Fig. 1.

\subsection{Data processing}

Radar data were processed through pulse compression, filtering, coherent stacking and incoherent stacking. Electromagnetic signal propagation speeds in ice is assumed to be a constant of $1.68 \times 10^{8} \mathrm{~m} / \mathrm{s}$ when transforming sampling time to depth. 


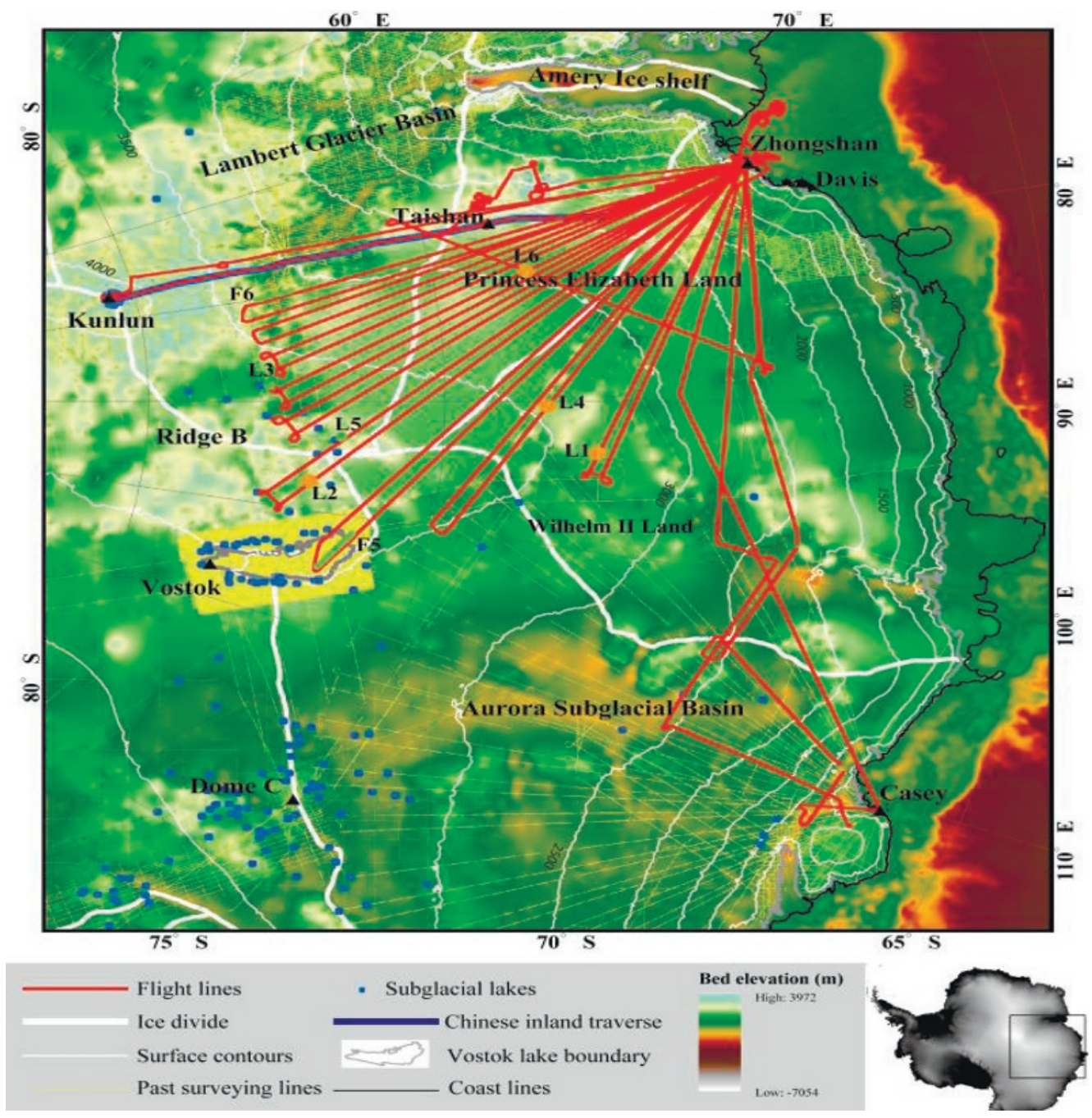

Fig. 1. The study area and flight lines coverage. Bedrock elevation and past surveying lines are both from Bedmap 2 [8], subglacial lakes are from [2], surface contours are from Bamber et al, 2009 [11]; Orange points (L1, L2, L4 and L6) show locations of new discovered lakes; Green points (L3 and L5) show locations of existed lakes; Green lines (F5 and F6) are radar profiles over Vostok lake and a very deep valley.

\section{Results}

Here, we show seven definite subglacial lakes (L1-L6 and Lake Vostok along F5 transect) detected by the radar system (Fig.1). Their locations are shown in orange points and green points in Fig.1 (L1-L6) and green line (Lake Vostok). Subglacial lakes are identifiable on radar profiles dueto their bright, flat and smooth appearance, compared with adjacent bedreflections [3]. L1, L2, L4 and L6 are believed to be new discovered subglacial lakes. We also confirmed another two subglacial lakes (L3 and L5) which were listed in [2]. The width ,buried depth and position of each lake along radargrams is shown in Fig. 2, 3 and 4, but the width of L3 is not correct because the flight line is a turn over the lake there. The Lake L6 is a large lake proposed by Jamieson et al., [9] with a width of $\sim 27 \mathrm{~km}$ along the 
radar line and buried depth of $\sim 3600 \mathrm{~m}$. The radargram from the flight over Lake Vostok is shown in Fig. 4. The flight line goes into the lake from its northern boundary where ice is thick and melting [1].

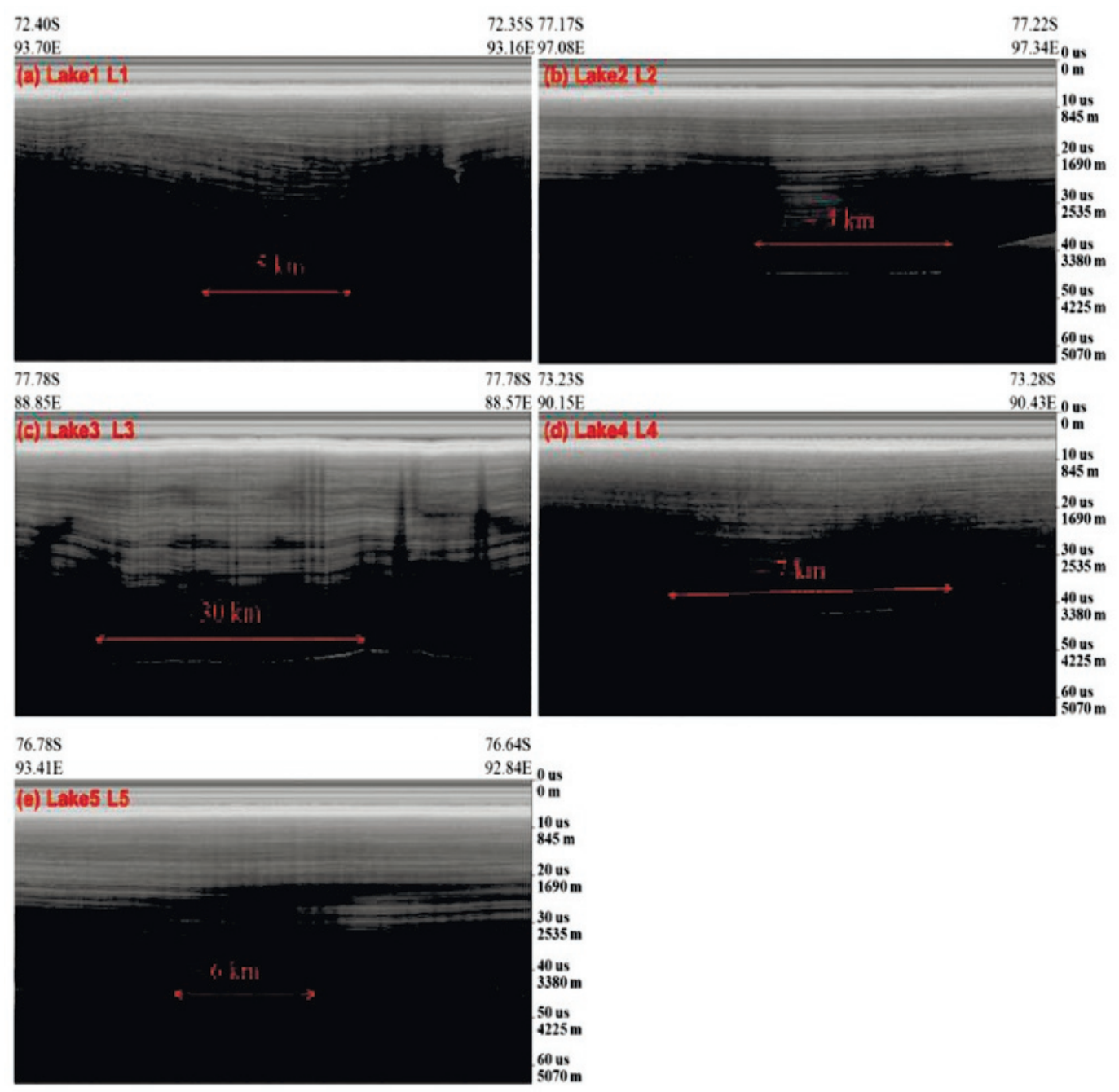

Fig. 2. Subglacial lakes (L1-L5 in Fig.1) detected by airborne RES in PEL. 


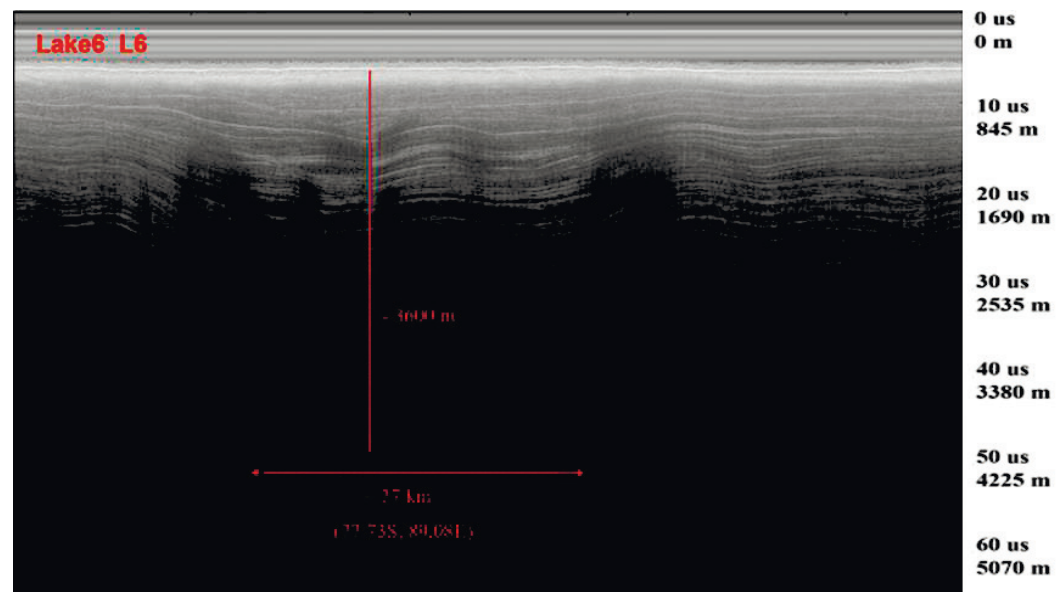

Fig. 3. The lake proposed by Jamieson et al, [9] from satellite data.

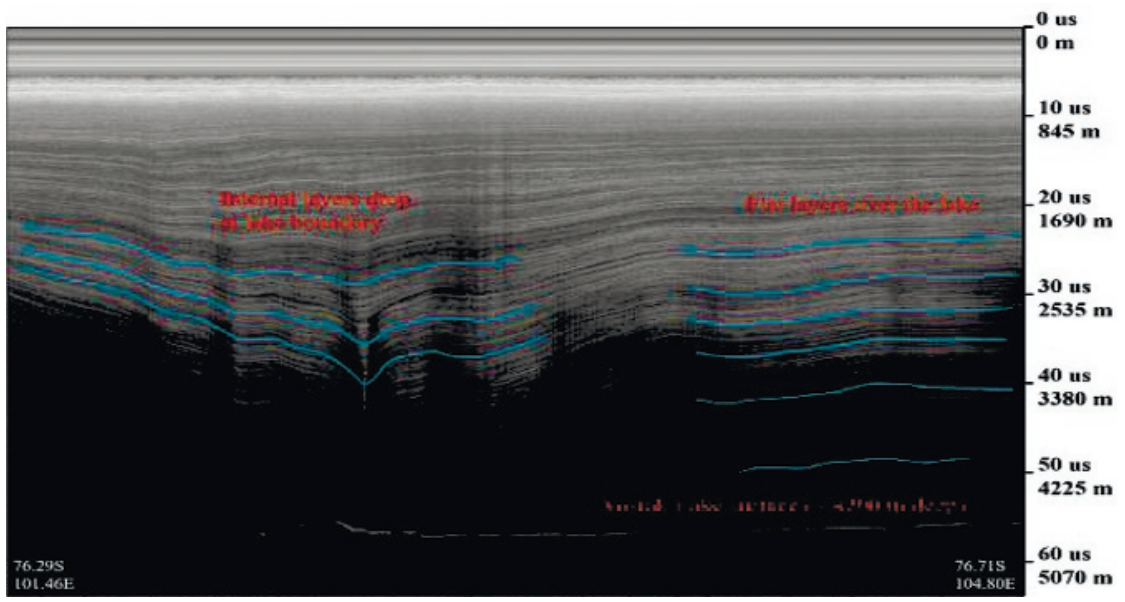

Fig. 4. Lake Vostok in radargram of F5 transect in Fig. 1. The blue curves denote the picked internal layers.

\section{References.}

1. Siegert, Martin J., Neil Ross, and Anne M. Le Brocq., Phil. Trans. Roy. Soc. A: Math. Phy. Eng. Sci. 374, 2059 (2016)

2. W. Andrew, M. Siegert., Antar. Sci. 24, 6 (2012)

3. Cui, X. B., Bo Sun, Gang Tian, Y. Y. Jiang, X. P. Zhang, J. X. Guo, X. Y. Tang., Adv. Earth Sci. 24, 4 (2009)

4. Young, D.A., Schroeder, D.M., Blankenship, D.D., Phil. Trans. Roy. Soc. A: Math. Phy. Eng. Sci. 374, 2059 (2016)

5. Bell, R.E., Ferraccioli, F., Creyts, T. T., Science 331, 6024 (2011)

6. Ellis-Evans, J. Cynan, David Wynn-Williams, Nature 381, 6584 (1996)

7. Christner, B.C., Priscu, J.C., Achberger, A.M., Barbante, C., Carter, S.P., Christianson, K., Michaud, A.B., Mikucki, J.A., Mitchell, A.C., Skidmore, M.L., Nature 512, 7514 (2014) 
8. Fretwell, P., Pritchard, H. D., Vaughan, D. G., Bamber, J. L., Barrand, N. E., Bell, R., Catania, G., The Cry. 7, 1 (2013).

9. Jamieson, S. S., Ross, N., Greenbaum, J. S., Young, D. A., Aitken, A. R., Roberts, J. L., Siegert, M. J., Geology 44, 2 (2016)

10. Cui, X., Greenbaum, J. S., Beem, L. H., Guo, J., Ng, G., Li, L., Sun, B., J. Env. Eng. Geophys. 23, 1 (2018)

11. Bamber, J. L., J. L. Gomez-Dans, J. A. Griggs., The Cry. 3, 1 (2009) 